\title{
WELDED BRACKET ASSEMBLY
}

\author{
Jan Hlavac, Jiri Dekastello \& Milan Cirek
}
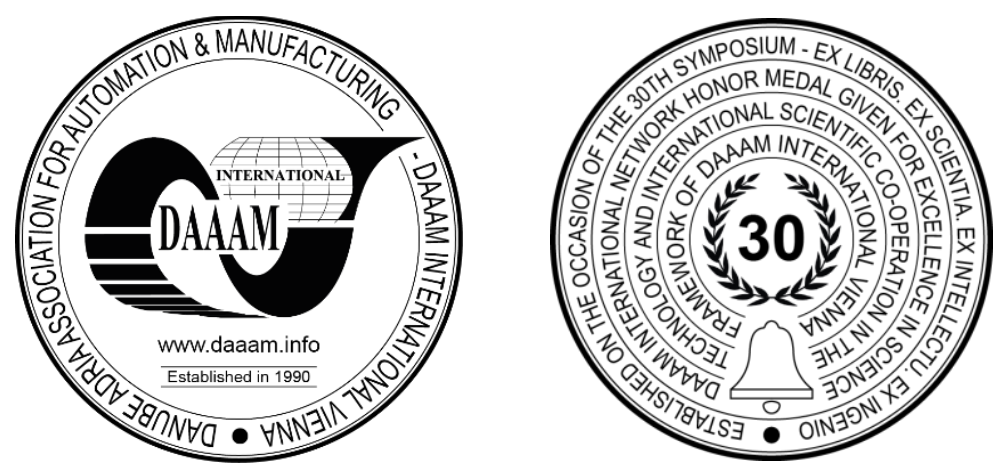

This Publication has to be referred as: Hlavac, J[an]; Dekastello, J[iri] \& Cirek, M[ilan] (2019). Welded Bracket Assembly, Proceedings of the 30th DAAAM International Symposium, pp.0775-0781, B. Katalinic (Ed.), Published by DAAAM International, ISBN 978-3-902734-22-8, ISSN 1726-9679, Vienna, Austria

DOI: $10.2507 / 30$ th.daaam.proceedings.107

\begin{abstract}
The paper deals with possibilities of structural design of welded bracket loaded by bending. The bracket assembly consists of an arm and a base that are connected to each other by a weld. Especially the weld on the side of the arm, which is stressed by tension, is adversely stressed. The design solutions are designed to provide sufficient strength while maintaining low production costs. The verification of the properties of individual designs was performed using 3D FEM. The resulting, optimal variant was achieved through the gradual improvement of the design solution - by learning from previous mistakes.
\end{abstract}

Keywords: bracket; weld; assembly; FEM; bending load

\section{Introduction}

The work presented in this paper follows the work presented in the past [1]. This is the work on the development of calenders for rubber processing, where the counter-movement of the working rolls is used. The work mentioned that the brackets are the most stressed parts, therefore the work is presented to them separately.

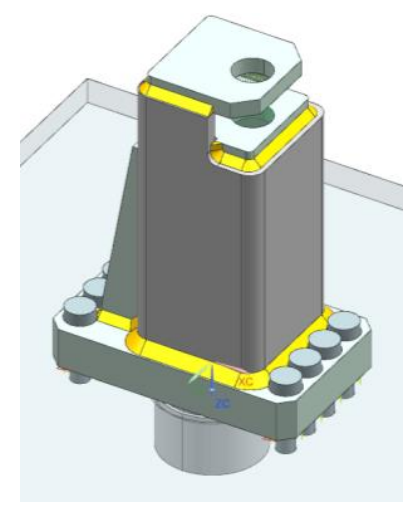

Fig. 1. Simplified model of counter-bend console - weldment 
The brackets themselves can be made from one piece of material by casting or from multiple parts by welding (see Fig. 1). In this work we focus only on the welded bracket, which ensures easy modifiability when used on a different machine. The bracket is attached to the calender stand by screws and its position is defined by a circular key. The screw connection is heavily stressed, but it is solved and is not the content of this article. The paper only mentions the method of creating the FEA model of a screw connection.

Welded bracket (see Fig. 2) typically consists of a base and an arm. The base is bolted to the sidewall and the arm is welded to the base. In its upper part the arm is fitted with a pin or holes for locating the pin on which the hydraulic cylinder is attached. Line of action of the force loading the bracket passes through the center of the pin and loads the arm by bending and thus the weld at the transition between the arm and the base.

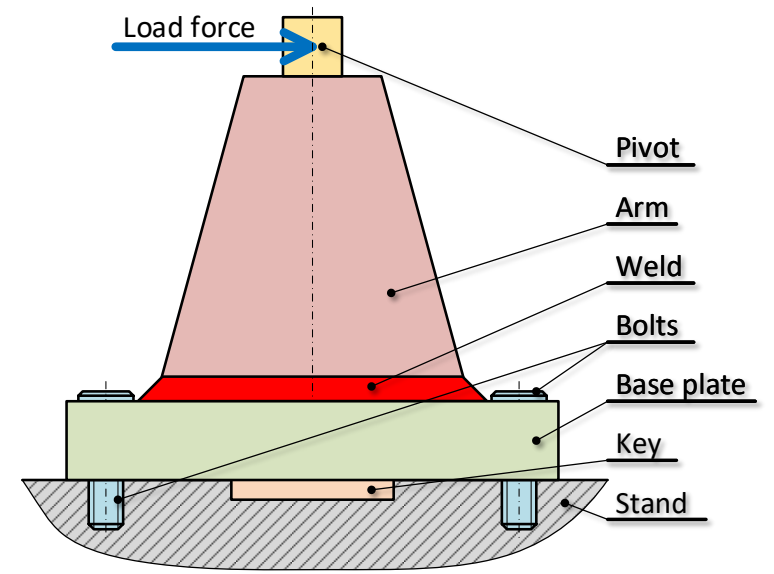

Fig. 2. Schematic example of the console including its load

The work pursues a variant design of a new console, which will be sufficiently strong, but also inexpensive to manufacture. The space options for the bracket design are limited. Topological optimization was not used to design the shape, which should lead to optimal use of the material [2], [3]. Topological optimization was not used because the console is a relatively simple load case and aims to maximize the use of metallurgical materials.

The resulting design of the console must meet all functional requirements placed on it, but it must also be economical. Although the design of the console may initially seem easy (it is a bent, fixed beam), the result may differ from the initial assumption.

\section{Bolted connection}

The whole FEA is realized as 3D. In order to minimize computational demands, a comparison of possible ways of simplifying the bolted connection was carried out [4], [5].

\subsection{Bolted connection - 1D prvek}

The first bolted connection model was created by the Bolt Connection function in the NX networking environment (see Fig. 3). This feature creates a solid spider on the face of the bracket as a bolt head and on the thread face in the hole in the plate. The two spiders are then connected by a 1D element that replaces the $30 \mathrm{~mm}$ diameter bolt shank.

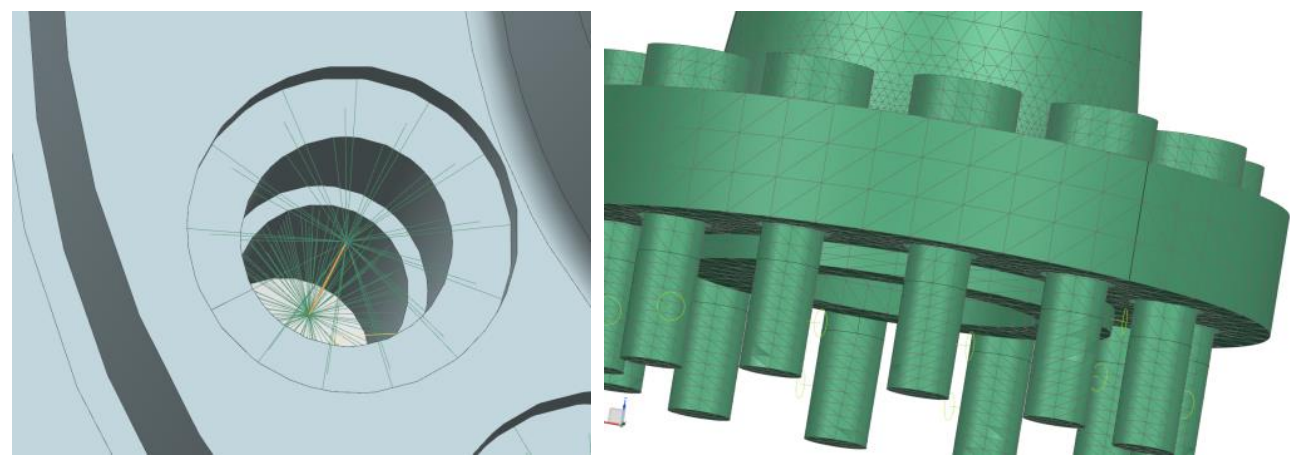

Fig. 3. Detail of bolted connection replacement with orange highlighted $1 \mathrm{D}$ element replacing the bolt shank (left) and detail of mesh of bolts including cut face (right) 


\subsection{Bolted connection - 3 D element}

The second computational model of the bolted connection consists of a 3D bolt model (see Fig. 2). The cylindrical surface of the bolt is cut perpendicularly at a distance of $45 \mathrm{~mm}$ from the end, as is the area in the bolt hole. These 45 millimetre cylindrical surfaces are firmly connected with hole surfaces by Mesh Mating, replacing the threaded connection. An offset contact has been set between the contact surface of the bolt head and the bracket.

\subsection{Bolted connection - boundary conditions}

In the computational model, between the contact surfaces of the console and the plate is set a contact. The coefficient of static friction in this contact is set to 0.25 . The whole model is firmly constrained on edges of the board as if it were part of a larger unit. The main load is applied to the area of the pin, on which the hydraulic cylinder or pull bar is attached. The cylinder loading force is $171806 \mathrm{~N}$.

Bolted connection - 1D element: Preload force applied on 1D elements substituting bolt shanks is set to $200 \mathrm{kN}$.

Bolted connection - 3D element: Offset value of the contact between bolt head and base of bracket is set to $0.12316 \mathrm{~mm}$, which is value of bolt deformation after applying preload of $200 \mathrm{kN}$.

\subsection{Bolted connection - simulation results}

The displacement value of the upper pin in the load direction is $2.47 \mathrm{~mm}$ when the $1 \mathrm{D}$ bolt replacement is used and $2.46 \mathrm{~mm}$ when the $3 \mathrm{D}$ screw model is used. This means that the displacement is very similar for both cases.
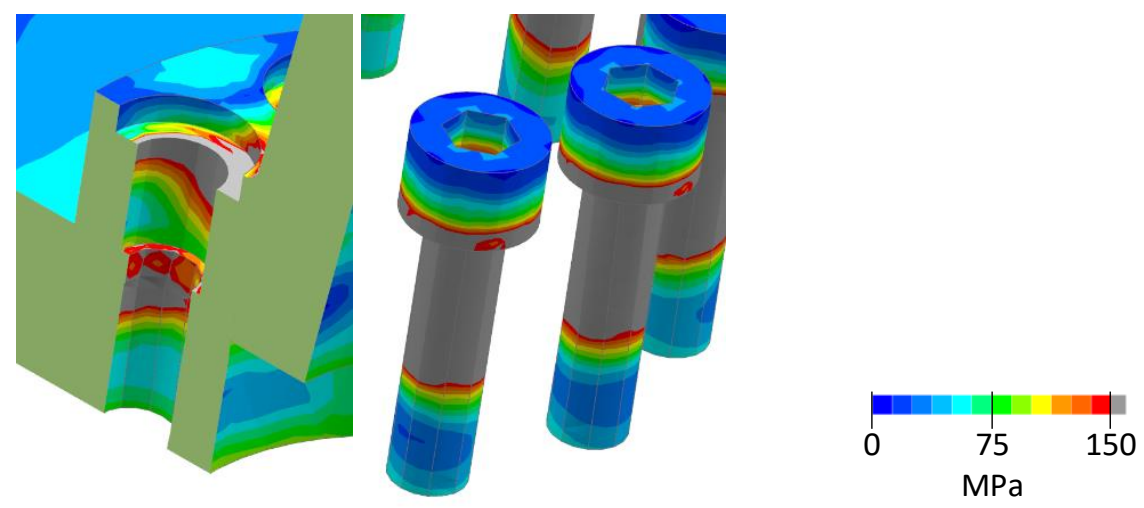

Fig. 4. Stress in bolted connection with load force, without deformation highlighting

The analysis showed that the maximum stress in the bolts is $536.8 \mathrm{MPa}$ (see Fig. 4). The material of the screws is 10.9 steel with a yield strength of $900 \mathrm{MPa}$, so the stress of the bolts is alright.

A comparison of the stress distribution in bolted joints shows that a computational model with 3D bolt models provides more realistic results.

\section{Variant bracket designs}

The idea is to design the console as a weldment, ideally from metallurgical semi-finished products. There is a strong pressure on production costs, so there should be as few machined surfaces as possible on the console.

The brackets are located on the outside of the calender stand. There are 8 of these brackets on the machine and are attached to the stand by eight M30 bolts. The following calculations are performed for $202 \mathrm{kN}$ load.

Welded consoles are modeled with the welded material admitted, a simulation approach that is already experimentally verified. Verification of welds can be performed analytically, but can be based on the conclusions of other works [6], [7], $[8]$.

\subsection{Bracket - variant 1}

It is a weldment of rolled square profile, with dimensions of 200x16, reinforcing ribs, base and plates with holes for pull bar-connecting bracket with working cylinder. The preloading force applied to the bolts is $60 \mathrm{kN}$ (see Fig. 5).

The computational connection of the individual parts of the bracket to the welds is realized by the Gluing function, which ensures that the nodes on the contact surfaces of both connected parts do not change their mutual distance during loading. The following are the results of calculating the first version of the console. 

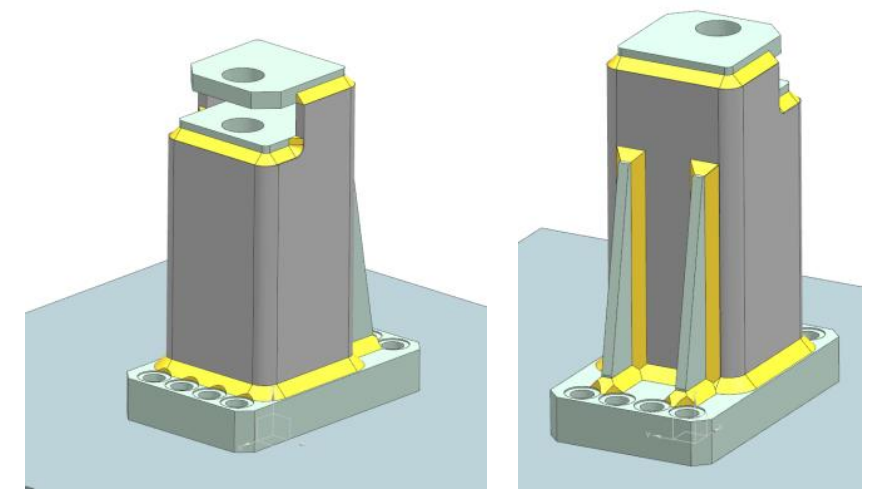

Fig. 5. Bracket variant 1 (welds in yellow)
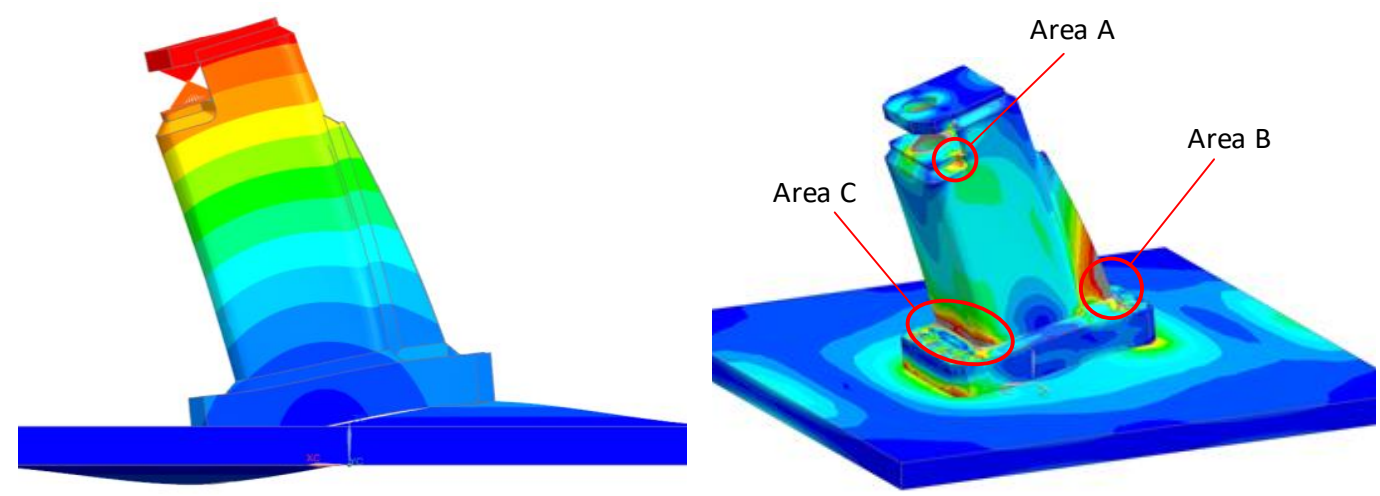

Fig. 6. Displacement (left) and stress distribution (right) on the bracket under load and designation of critical areas

This bracket is very strained and therefore the stresses that arise under loads far exceed the bearable limits (see

Fig. 1. 6). High stress occurs in the ribs and the heel of the profile (area B - tension and C - compression). Next area of high stress is the lower pin plate itself or at the weld location (area A).

\subsection{Bracket-variant 2}

For further computation, the model was changed to minimize the stresses generated. Specifically:

- Increased rib thickness from $15 \mathrm{~mm}$ to $20 \mathrm{~mm}$,

- Increased thickness of the profile wall from 16 to $20 \mathrm{~mm}$

- Used 3D model of bolts.

Also in the second model there are again stress peaks on the pin plate and its surroundings (area A).

\subsection{Bracket-variant 3}
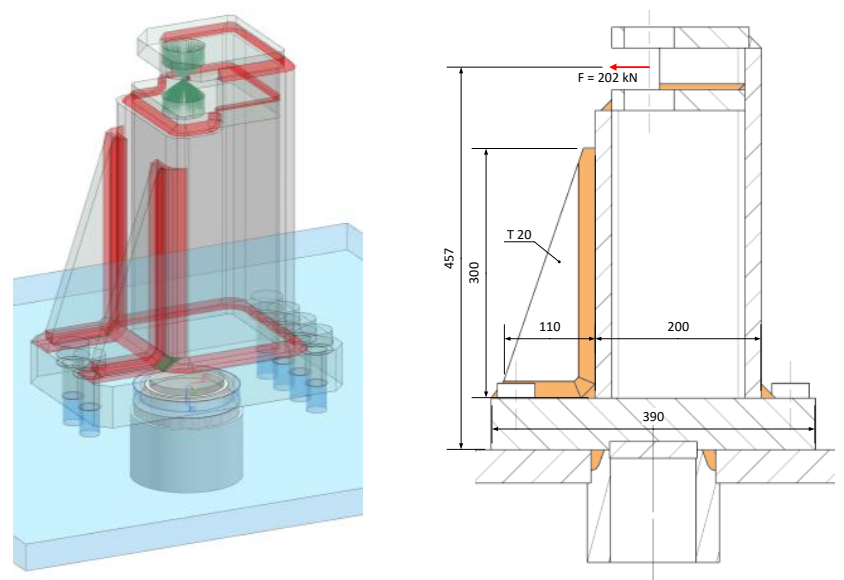

Fig. 7. Bracket variant 3 
The idea is to turn the bracket load around. Move the reinforcing ribs to the compression side of the bracket (see Fig. 7) so that the ribs weld is pressed instead of pulled = more favourable load. The model is based on previous variant. The ribs were enlarged - at the expense of removing two bolts from the compression side of bracket base.

The weld stress in area B again exceeds the permissible stress values.

\subsection{Bracket - variant 4}

Four larger ribs located on both the tension and compresion sides of the rolled profile (see Fig. 8). On the pressure side again only two bolts - more space for the ribs. Bracket base extended.
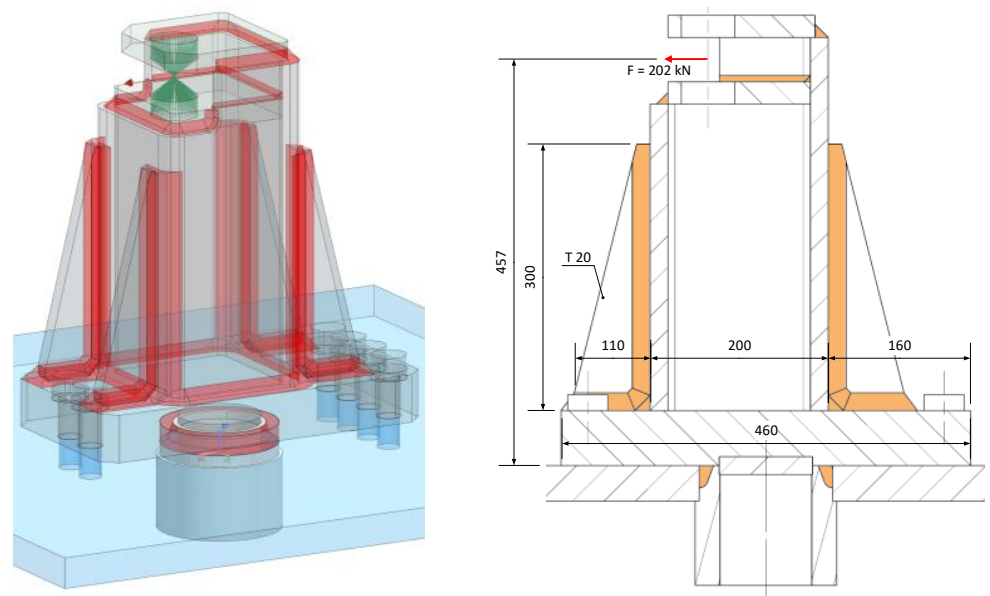

Fig. 8. Bracket variant 4

The weld stress in area B again exceeds the permissible stress values.

\subsection{Bracket - variant 5}

The rolled profile was removed from the bracket design and was replaced by two plates (see Fig. 9).

Since, due to the shape of the bracket, the question was how this design would react to loading by off-axis force, a computational model was loaded by $5^{\circ}$ off-axis force and simulation was further carried out.

The stress in the whole bracket is under permissible limit, but due to the increased rigidity in the base plate, the contact pressure between the bracket and the stand has increased significantly.
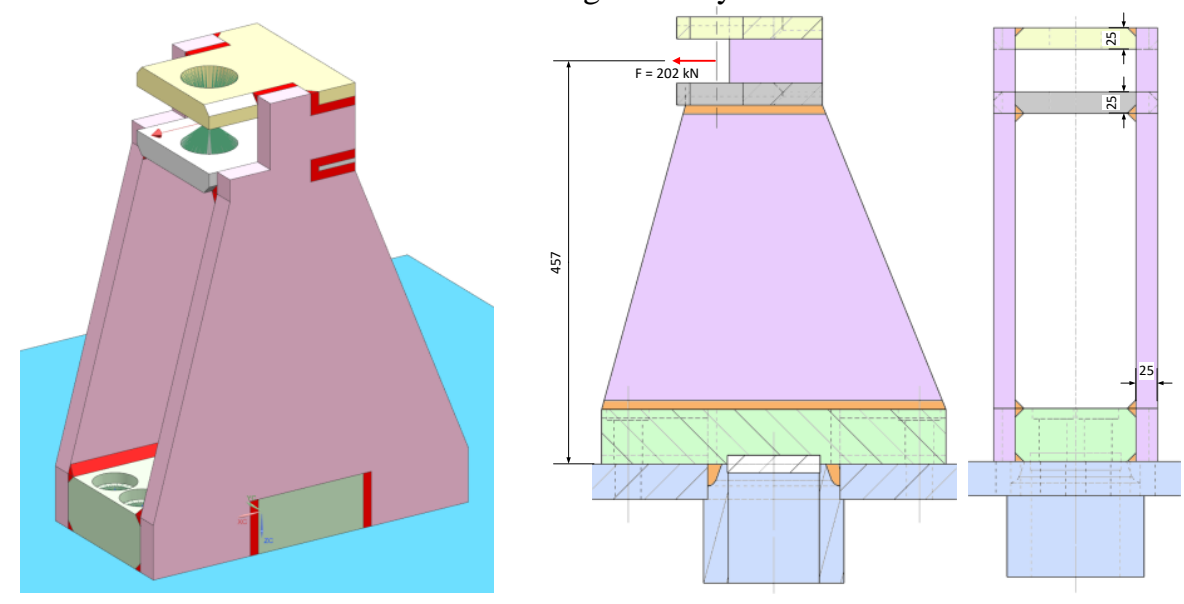

Fig. 9. Bracket variant 5 


\subsection{Bracket - variant 6}

The rolled profile was removed from the bracket design and was replaced by one thick plate (see Fig. 10). The base plate is welded with bracket into one piece. Bracket assembly is then connected to nut plate (T $40 \mathrm{~mm}$ ) by $10 \mathrm{xM} 30$ bolts (preload force $160 \mathrm{kN}$ ) that go through stand plate.
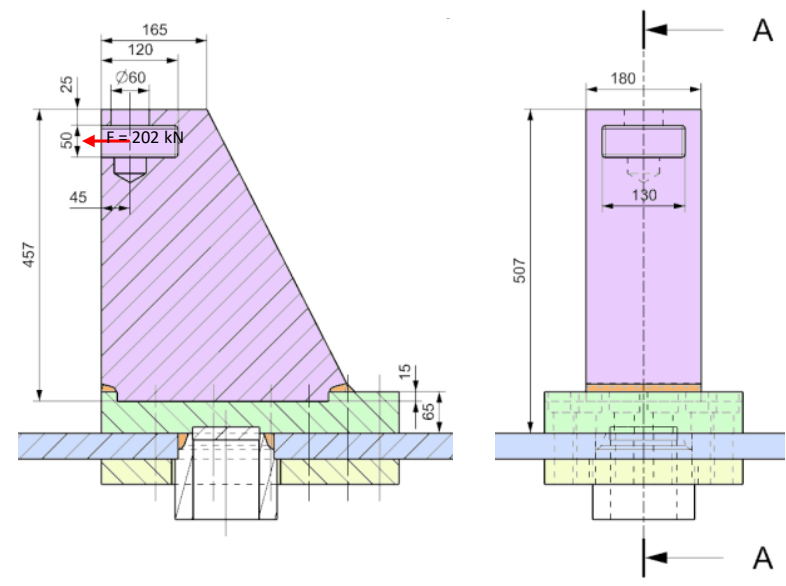

Fig. 10. Bracket variant 5

The stress on the bracket of variant 6 is already within acceptable limits.

Although it is clearly the most massive variant, its production will be relatively simple, and therefore even undemanding. With minor modifications, it will be used on a real machine.

\section{Conclusion}

The work is devoted to design of welded bracket, co that it is sufficiently durable and easily manufacturable. In this work we have proceeded from our previous knowledge (e.g. how to simulate a weld in FEM environment), but also from other published results. The designed brackets are made of conventional metallurgical semi-finished products.

The first variants had a bracket arm made of rolled profile, but this proved to be inadequate, especially in the area of the weld between the arm and the base plate. Even the addition of support ribs (on the tension and/or compression side) did not lead to a satisfactory result.

This was followed by a different variant built entirely of sheet metal, which was good in strength. Its considerable bending stiffness has adversely affected the increase in contact pressure between the bracket and the stand, which could lead to deformation by compression.

The last variant has an arm made of thick sheet metal, which leads to its considerable weight. However, its workload characteristics are the most balanced.

The result of the final console variant was unexpected. It showed the fact that it is always necessary to look for optimal properties and not only the maximum result of the monitored parameter. In the course of the solution, another variant was created. For example, by using a pre-stressing, a compression stress was induced in the weld, which only became tensile under load. The result of such variants was satisfactory, but production costs would be disproportionately increased. In any case, this is a variant that will be subject to further in-depth research.

\section{Acknowledgments}

This article was done by financial support SGS-2019-001 of University of West Bohemia.

\section{References}

[1] Dekastello, J.; Hlavac, J. \& Cirek, M., (2018). Replacement of a Cast Stand of a Rubber Machine With a Welded Stand, Proceedings of the 29th DAAAM International Symposium, pp.0594-0600, B. Katalinic (Ed.), Published by DAAAM International, ISBN 978-3-902734-20-4, ISSN 1726-9679, Vienna, Austria, DOI: 10.2507/29th.daaam.proceedings.086

[2] Li, X. P.; Zhao, L. Y., \& Liu, Z. Z. (2017). Topological optimization of continuum structure based on ANSYS. In MATEC Web of Conferences (Vol. 95, p. 07020). EDP Sciences.

[3] Gunwant, D. \& Misra, A. (2012). Topology Optimization of sheet metal brackets using ANSYS. MIT International Journal of Mechanical Engineering, 2(2), pp. 120-126. 
[4] Jeong, K.; Joo-Cheol, Y. \& Beom-Soo, K. (2006). Finite element analysis and modeling of structure with bolted joints, Applied Mathematical Modelling, Vol. 31, Issue 5, 2007, pp. 895-911., ISSN: 0307-904X, DOI: https://doi.org/10.1016/j.apm.2006.03.020

[5] Valladares, D., Carrera, M., Castejon, L., \& Martin, C. (2013). Development of a Numerical Technique for the Static Analysis of Bolted Joints by the FEM. In Proceedings of the World Congress on Engineering (Vol. 3, pp. 3-5).

[6] Krejsa, M., Brozovsky, J., Mikolasek, D., Parenica, P., \& Halama, R. (2015). Experimental verification of a steel fillet welded joint model. In Proc. of the Fifteenth Int. Conf. on Civil, Structural and Environmental Engineering Computing (J. Kruis, Y. Tsompanakis \& BHV Topping eds.), Civil-Comp Press, DOI (Vol. 10)

[7] Krejsa, M., Brozovsky, J., Mikolasek, D., Parenica, P., Koubova, L., \& Materna, A. (2017). Numerical modeling of fillet and butt welds in steel structural elements with verification using experiment. Procedia engineering, 190, pp. 318-325.

[8] Deng, D., Murakawa, H., \& Liang, W. (2007). Numerical simulation of welding distortion in large structures. Computer methods in applied mechanics and engineering, 196(45-48), pp. 4613-4627. 